\title{
A COMPETÊNCIA EM INFORMAÇÃO E SUA AVALIAÇÃO SOB A ÓTICA DA MEDIAÇÃO DA INFORMAÇÃO: REFLEXÕES E APROXIMAÇÕES TEÓRICAS
}

\author{
LA ALFABETIZACIÓN Y SUA EVALUACIÓN DESDE LA \\ PERSPECTIVA DE LA MEDIACIÓN DE LA INFORMACIÓN: \\ REFLEXIONES Y APROXIMACIONES TEÓRICAS
}

\begin{abstract}
Regina Célia Baptista Belluzzo - rbelluzzo@gmail.com Doutora em Ciências da Comunicação pela Universidade de São Paulo (USP). Professora do Programa de Pós-Graduação em Ciência da Informação da Universidade Estadual Paulista (UNESP/Marília).

Camila Araújo dos Santos - camilaar_santos@hotmail.com Doutoranda do Programa de Pós-Graduação em Ciência da Informação da Universidade Estadual Paulista (UNESP/Marília).

Oswaldo Francisco de Almeida Júnior - ofaj@ofaj.com.br Doutor em Ciências da Comunicação pela Universidade de São Paulo (USP). Professor do Programa de Pós-Graduação em Ciência da Informação da Universidade Estadual Paulista (UNESP/Marília).
\end{abstract}

\section{RESUMO}

Introdução: $O$ estudo discute a aproximação teórica existente entre as temáticas competência em informação e sua avaliação com a mediação da informação.

Objetivo: Expor, por meio da analogia entre as temáticas (competência em informação e sua avaliação e a mediação da informação), as similaridades entre estes processos a fim de proporcionar melhor compreensão para a aplicabilidade dos mesmos.

Metodologia: A pesquisa é de natureza qualitativa e tem caráter bibliográfico. 
Regina Célia Baptista Belluzzo; Camila Araújo dos Santos; Oswaldo Francisco de Almeida Júnior

A competência em informação e sua avaliação sob a ótica da mediação da informação: reflexões e aproximações teóricas

Resultados: Como resultados, verificou-se que a competência em informação é uma ação de interferência, assim como a mediação da informação, pois ambas preocupam-se com a formação de um cidadão crítico e reflexivo frente o mundo informacional. A avaliação da competência em informação é uma forma de verificar se a apropriação da informação foi internalizada pelas pessoas.

Conclusões: $O$ desenvolvimento da competência em informação e sua avaliação sob a ótica da mediação da informação são ações de interferência que propiciam a construção do conhecimento crítico e reflexivo nas pessoas para a internalização de atitudes pró-ativas para o acesso e uso da informação de forma inteligente na sociedade contemporânea.

Palavras-chaves: Competência em informação. Avaliação da competência em informação. Mediação da informação.

\section{INTRODUÇÃO}

Com o aumento do contingente informacional, em grande parte, proveniente do advento das tecnologias, qualquer pessoa em qualquer lugar tem acesso a um vasto "mar" de recursos e fontes informacionais, os quais, muitas vezes, apresentam informações não confiáveis, conflitantes e tendenciosas e que podem causar, inclusive, a "desinformação".

Neste cenário, é necessário que as pessoas tenham competências e habilidades em informação para reconhecer suas necessidades informacionais, buscar, selecionar, avaliar criticamente e compartilhar a informação em diversas fontes. Estas ações são compreendidas como competência em informação.

A competência em informação, considerada como um processo que tem por finalidade desenvolver competências e habilidades informacionais para aprimorar o pensamento crítico e analítico das pessoas em relação ao universo informacional, pode ser implementada e desenvolvida em bibliotecas por meio de programas com o apoio de mediadores - bibliotecários e professores.

Por ser um processo que envolve o desenvolvimento e aprimoramento de atitudes relativas à busca, recuperação, avaliação e disseminação da informação, a mediação da informação é inerente à competência em informação, já que é uma ação de interferência.

Partindo destes pressupostos, buscamos apontar algumas reflexões e aproximações entre a competência em informação e sua avaliação sob a ótica da 
Regina Célia Baptista Belluzzo; Camila Araújo dos Santos; Oswaldo Francisco de Almeida Júnior

A competência em informação e sua avaliação sob a ótica da mediação da informação: reflexões e aproximações teóricas

mediação da informação. Neste sentido, são expostos os três temas, por meio da construção de um referencial teórico, de maneira que se pudesse extrair deste a relevância das duas temáticas para uma análise e discussão teórica sobre a transposição dos princípios que envolvem a mediação da informação.

Levando em consideração que a mediação da informação está "[...] presente em todas as ações do bibliotecário, em todo o fazer desse profissional" (ALMEIDA JUNIOR, 2008, p. 46), entende-se que a competência em informação, assim como sua avaliação, fazem parte deste processo, pois a primeira permite 0 desenvolvimento de competências e habilidades informacionais para a apropriação da informação e, a segunda, verifica se as pessoas apropriaram-se das competências e habilidades desenvolvidas.

\section{PROCEDIMENTOS METODOLÓGICOS}

A pesquisa é de natureza qualitativa e tem caráter bibliográfico. A pesquisa bibliográfica "[...] é desenvolvida a partir de material já elaborado, constituído principalmente de livros e artigos científicos." (GIL, 2012, p. 50).

Trata-se ainda de uma "pesquisa de base", pois "[...] oferece dados elementares que dão suporte para a realização de estudos mais aprofundados sobre o tema" (GONSALVES, 2001, p. 65).

Os dados para análise foram retirados de artigos científicos sobre os temas, com enfoque nas seguintes categorias de análise: a) Competência em informação e medição da informação: aproximações; e b) Reflexões teóricas sobre a avaliação da competência em informação e mediação da informação.

\section{COMPETÊNCIA EM INFORMAÇÃO E MEDIAÇÃO DA INFORMAÇÃO: APROXIMAÇÕES}

A informação sempre foi e será um recurso básico para o desenvolvimento em qualquer campo do conhecimento e da atividade humana.

O simples acesso à informação "[...] não é mais suficiente. Busca-se então, formas e processos que permitam filtrar toda esta informação - avaliação crítica, critérios de relevância, pertinência, interpretação, organização etc." (VARELA, 2006, 
Regina Célia Baptista Belluzzo; Camila Araújo dos Santos; Oswaldo Francisco de Almeida Júnior

A competência em informação e sua avaliação sob a ótica da mediação da informação: reflexões e aproximações teóricas

p.18). Para as pessoas manterem-se atualizadas e tomarem decisões pertinentes à resolução de seus problemas, ou seja, condizente com sua necessidade informacional, é imprescindível que dominem o uso de ferramentas, suportes tecnológicos e diversos recursos informacionais priorizando a busca, recuperação, avaliação crítica e disseminação da informação. Estas ações são chamadas de competência em informação.

A competência em informação pode ser definida como um conjunto de competências e habilidades que uma pessoa necessita incorporar para lidar, de forma crítica e reflexiva, com os diversos recursos informacionais existentes (jornais, revistas, livros, dicionários, enciclopédias, Internet, etc.).

Os termos "competências" e "habilidades" *, muitas vezes compreendidos como sinônimos, devem ser diferenciados para melhor compreensão de todo o processo da competência em informação:

- Competências: constituem um conjunto de conhecimentos, atitudes, capacidades e aptidões que habilitam alguém para vários desempenhos da vida. As competências pressupõem operações mentais, capacidades para usar as habilidades e emprego de atitudes adequadas à realização de atividades e conhecimentos.

- Habilidades: acham-se ligadas a atributos relacionados não apenas ao saber-conhecer, mas ao saber-fazer, saber-conviver e ao saber-ser.

A competência em informação surgiu pela primeira vez na literatura, em 1974, nos Estados Unidos, em um relatório intitulado The information service environment relationships and priorities, de autoria do bibliotecário americano Paul Zurkowski, com a expressão InformationLiteracy.

No Brasil, a prática e os fundamentos da competência em informação sempre estiveram intrínsecos no fazer do profissional bibliotecário em situações específicas

\footnotetext{
* Material didático utilizado pelas professoras Dra. Regina Célia Baptista Belluzzo e Dra. Glória Georges Feres para a disciplina "Competência em informação, redes de conhecimento e inovação" no Programa de Pós-Graduação em Ciência da Informação da Universidade Estadual Paulista (UNESP) - Marília, 2013.
} 
Regina Célia Baptista Belluzzo; Camila Araújo dos Santos; Oswaldo Francisco de Almeida Júnior

A competência em informação e sua avaliação sob a ótica da mediação da informação: reflexões e aproximações teóricas

de uso da biblioteca e de seus recursos informacionais, porém, com outra "roupagem": a educação de usuários, definida como

[...] o processo pelo qual o usuário interioriza comportamentos adequados com relação ao uso da biblioteca e desenvolve habilidades de interação permanente com os sistemas de informação. (BELLUZZO, 1989, p. 37).

A educação de usuários perpassa outras ações (cada uma com suas peculiaridades) que vão desde a formação até a aprendizagem. Belluzzo (1989, p. 37), como forma de melhor esclarecer cada ação, explicitou a diferença entre elas, a saber:

- Formação: aquisição de conhecimentos e desenvolvimento de atitudes e habilidades, de acordo com o tipo de usuário de biblioteca (docente, discente, pesquisador etc.) previamente definido;

- Treinamento: ações e/ ou estratégias para desenvolver determinadas habilidades do usuário por desconhecer situações específicas de uso da biblioteca e de seus recursos informacionais, envolvendo o conjunto de meios necessários para tal;

- Instrução: descrição rigorosa de procedimentos acompanhada de pormenores, para o usuário manejar eficientemente os recursos informacionais da biblioteca;

- Orientação: ação de esclarecer o usuário sobre a organização da biblioteca, "layout" e serviços oferecidos. Tem um sentido mais abrangente do que a instrução;

- Ensino: processo formal e intencional voltado para o usuário cujo objetivo é propiciar condições para seu desempenho efetivo no uso da biblioteca e dos recursos informacionais;

- Aprendizagem: aquisição de novo comportamento e / ou modificação de atitude do usuário frente ao uso da biblioteca e dos recursos informacionais, mediante a assimilação do que foi ensinado por meio de orientação ou instrução. 
Regina Célia Baptista Belluzzo; Camila Araújo dos Santos; Oswaldo Francisco de Almeida Júnior

A competência em informação e sua avaliação sob a ótica da mediação da informação: reflexões e aproximações teóricas

A competência em informação assume contornos diferentes em relação à educação de usuários e "dá um passo além”, uma vez que prioriza o aprendizado ao longo da vida, fazendo com que os processos investigativos e a construção de conhecimento permeiem todas as ações aplicáveis a qualquer situação, seja junto aos sistemas formais, seja junto aos informais (DUDZIAK, 2001, p. 59).

O desenvolvimento da competência em informação, segundo Belluzzo (2008), requer um tratamento que envolve desde a compreensão da informação em seu sentido amplo e as exigências das sociedades humanas, dependendo fundamentalmente da educação, recomendando-se que haja um trabalho integrado entre educadores e bibliotecários no sentido de:

- Preparação de diretrizes básicas para iniciativas conjuntas sob o enfoque das necessidades da sociedade da informação e dos princípios da Competência em Informação, uma atividade intra-curricular.

- Definir as condições para que tais iniciativas possam ser apoiadas por políticas e pelas comunidades assistidas.

- Implementar e criar mecanismos de manutenção e avaliação das práticas pedagógicas e informacionais.

Ressalta-se que o conceito de competência traz à tona várias concepções, porém, vamos entendê-la como sendo um composto de duas dimensões distintas: a primeira, um domínio de saberes e habilidades de diversas naturezas que permitem a intervenção prática na realidade e, a segunda, uma visão crítica do alcance das ações e o compromisso com as necessidades mais concretas que emergem e caracterizam o atual contexto social. Desse modo, fundamentando-nos nessa dupla dimensão da competência é que se situa a Competência em Informação (BELLUZZO, 2008).

Desse modo, entendida a partir dessa duplicidade de dimensões e como um conjunto de competências e habilidades que são desenvolvidas por meio de atividades de busca, recuperação, avaliação e apropriação da informação, estruturadas e aplicadas por bibliotecários e professores, entende-se que esta é indissociável à mediação da informação, a qual consiste em 
Regina Célia Baptista Belluzzo; Camila Araújo dos Santos; Oswaldo Francisco de Almeida Júnior

A competência em informação e sua avaliação sob a ótica da mediação da informação: reflexões e aproximações teóricas

[...] toda ação de interferência, realizada pelo profissional da informação, direta ou indireta; consciente ou inconsciente, singular ou plural; individual ou coletiva; que propicia a apropriação da informação que satisfaça, plena ou parcialmente, uma necessidade informacional. (ALMEIDA JUNIOR, 2009, p. 92).

A mediação da informação surge de um vácuo teórico do Serviço de Referência e Informação, principalmente a partir de meados dos anos 1990. É possível que a expressão 'vácuo teórico' não seja apropriada, dado que nunca houve propostas teóricas específicas para esse Serviço, mas modelos, práticas e metodologias voltadas para o atendimento de usuários. Em meados dos anos 1990, portanto, esses modelos, práticas e metodologias passaram a focar não o Serviço de Referência e Informação em seu todo, mas aspectos pontuais dele. A mediação da informação passa a ocupar esse vazio de concepções ou, melhor dizendo, inicia o processo de refletir sobre as ações desenvolvidas pelos equipamentos informacionais em seu relacionamento com seus usuários.

Os estudos sobre mediação da informação, a partir daquele momento, deslocaram a ênfase sobre o atendimento ao usuário para abarcar todo o fazer do profissional da informação. Desse modo, na visão de Almeida Júnior, teríamos a mediação explícita da informação, ocorrendo no Serviço de Referência e Informação, e a mediação implícita da informação. Esta, por sua vez, ocorre

[...] de maneira não explicitada, na seleção, na escolha dos materiais que farão parte do acervo da biblioteca, em todo o trabalho do processamento técnico, nas atividades de desenvolvimento de coleções e, também no serviço de referência e informação. Presente em todas essas ações, a mediação faria parte do próprio objeto da área de informação. Especificamente, em relação à área de Ciência da Informação, o seu objeto passaria a ser mais a mediação do que a informação. (ALMEIDA JÚNIOR, 2008, p. 46).

No senso comum dos profissionais da informação, a mediação da informação é considerada como algo já intuitivamente assimilado, apreendido e compreendido. Mas, "[...] verifica-se que a mediação da informação é um termo que se apresenta amplamente no discurso dos profissionais da informação, mas não nas suas práticas profissionais" (ALMEIDA JÚNIOR, 2009, p. 91-92). 
Regina Célia Baptista Belluzzo; Camila Araújo dos Santos; Oswaldo Francisco de Almeida Júnior

A competência em informação e sua avaliação sob a ótica da mediação da informação: reflexões e aproximações teóricas

Assim sendo, a área identifica a mediação da informação como uma ponte que permite o relacionamento entre dois pontos, o universo informacional e a comunidade a ser servida, que de alguma maneira estão impedidos por meio de obstáculos de interagir, além de ser considerada como sinônimo de transferência de informação, disseminação da informação ou distribuição da informação (ALMEIDA JÚNIOR, 2009, p. 92).

Porém, tal imagem é inadequada, uma vez que oferece "[...] a ideia de algo estático, que leva alguma coisa de um ponto a outro, sendo estes predeterminados e fixos, e que não interfere no trajeto, no modo de caminhar e no final do percurso" (ALMEIDA JÚNIOR, 2009, p. 92). Ou seja, a mediação da informação é entendida como uma ação em que o profissional da informação só presta atendimento ao usuário como um intermediário que não tem o poder de interferir, e que deve ser neutro e imparcial. No que tange à execução das atividades inerentes ao profissional da informação, por mais que ele busque a imparcialidade, sempre vai haver algum tipo de interferência. Almeida Júnior (2009, p. 94) complementa:

\begin{abstract}
A interferência não deve ser negada, mas, sim, explicitada, afirmada, tornada consciente para que, criticamente, o profissional possa lidar com ela de maneira a amenizar / minimizar possíveis problemas que dela decorram. Há uma linha tênue entre interferência e manipulação. A consciência de sua existência, bem como da realidade da interferência, permite não a eliminação da manipulação, mas a diminuição de seus riscos e de suas consequências.
\end{abstract}

A informação é mediada para que seja apropriada pela pessoa, pois a apropriação "[...] pressupõe uma alteração, uma transformação, uma modificação do conhecimento" (ALMEIDA JUNIOR, 2007, p.36).

Desta forma, considerando que a mediação faz parte de toda ação do profissional, entende-se que a competência em informação pode ser incluída em tal processo, visto que se constitui por atividades que objetivam desenvolver o senso crítico das pessoas em relação ao uso da informação.

A mediação da informação, assim como a competência em informação, são ações de interferência realizadas por mediadores no processo de ensinoaprendizagem de competências e habilidades informacionais em uma biblioteca, por exemplo. O mediador interfere para que haja uma mobilização de conhecimentos e 
Regina Célia Baptista Belluzzo; Camila Araújo dos Santos; Oswaldo Francisco de Almeida Júnior

A competência em informação e sua avaliação sob a ótica da mediação da informação: reflexões e aproximações teóricas

[...] internalização de fundamentos conceituais, atitudinais e de habilidades específicas como referenciais à compreensão da informação e de sua abrangência, em busca da fluência e das capacidades necessárias à geração do conhecimento novo e sua aplicabilidade legal e ética ao cotidiano das pessoas e das comunidades ao longo da vida. (BELLUZZO, 2001).

Compreendemos que é a partir da internalização de competências e habilidades informacionais que a apropriação da informação é "ativada", pois a pessoa consegue, de certa forma, avaliar todo o contexto em que está inserida e satisfazer suas necessidades informacionais.

Mediar e desenvolver competências e habilidades, relacionadas à busca e recuperação da informação, são processos que possibilitam a interação, entre mediador e mediado e que ativam e potencializam a construção do conhecimento pelos mediados. São processos que modificam, alteram e transformam os estímulos (ação de interferência) do mediado, proporcionando-lhe uma postura ativa, crítica, reflexiva e independente frente à pesquisa de informações para a satisfação de necessidades informacionais.

Quando a pessoa sofre uma ação de interferência do mediador em relação à busca e recuperação da informação, ela percebe quando a informação é necessária, expressa ideias, desenvolve argumentos, refuta opiniões alheias baseando-se em conhecimentos e habilidades construídos, avalia criticamente a informação e suas implicações na sociedade, mantendo-se informado (DUDZIAK, 2002). A verdadeira mediação educacional "[...] ocorre quando o bibliotecário convence o aprendiz de sua própria competência, incutindo-Ihe autoconfiança para continuar o aprendizado, transformando-o em um aprendiz autônomo e independente." (DUDZIAK, 2003, p. 33).

Desenvolver competências e habilidades em informação não significa moldar a pessoa para a sociedade, mas sim, mostrar que a partir de todo este novo conhecimento que Ihe foi atribuído a partir da mediação da informação, há a possibilidade de tornar-se um cidadão que reflete sobre a sociedade em que vive, que reivindica direitos e sabe exercer sua cidadania.

A competência em informação mostra os "caminhos que devem ser trilhados" por uma pessoa no momento da busca e recuperação da informação. Para que este caminho seja trilhado de forma eficaz e eficiente, a prática da avaliação deve ser 
Regina Célia Baptista Belluzzo; Camila Araújo dos Santos; Oswaldo Francisco de Almeida Júnior

A competência em informação e sua avaliação sob a ótica da mediação da informação: reflexões e aproximações teóricas

uma constante, já que é ela que determina aquilo que é importante ou não para a satisfação das necessidades informacionais.

\section{REFLEXÕES TEÓRICAS SOBRE A AVALIAÇÃO DA COMPETÊNCIA EM INFORMAÇÃO E A MEDIAÇÃO DA INFORMAÇÃO}

A ação de avaliar está presente no nosso dia-a-dia: avaliamos tudo aquilo que corresponde as nossas necessidades vitais e informacionais. Inserir a prática de avaliação no cotidiano é fundamental para o julgamento daquilo que é ou não pertinente para a nossa vida, ou seja, sempre buscamos comparar os resultados obtidos com os esperados.

No âmbito da competência em informação não é diferente. De acordo com a American Association of School Librarians (ASSL, 1998), a avaliação da competência em informação pode ser entendida como uma experiência de reflexão acerca da aprendizagem das pessoas e uma reflexão sobre a estruturação de programas de desenvolvimento da information literacy.

A avaliação não é uma atividade que só é praticada ao fim do trabalho de desenvolvimento de competências e habilidades em informação, mas uma forma de melhorar a aprendizagem e o desempenho das pessoas durante as atividades de competência em informação, como também a de acusar lacunas e apontar melhorias em programas de desenvolvimento da competência em informação.

A avaliação deve ser uma atividade sistemática e contínua, integrada ao processo educativo, que tem como objetivo proporcionar o maior número de informação para a melhoria desse processo, reajustando seus objetivos, revisando projetos e programas, métodos e recursos, além de servir como base para determinar se a aprendizagem do aluno está ocorrendo de fato (ARENAS, 2007). Tal argumento é similar ao de Almeida Junior (2003, p. 104), no qual expõe que a avaliação:

Inicia-se ou deve se iniciar na própria formulação do projeto de serviço e caminhar com a implantação dele. Deve estar presente sempre, durante o período em que esse serviço existir. Deve também modificar, alterar, reestruturar os serviços, de acordo com os resultados. 
Regina Célia Baptista Belluzzo; Camila Araújo dos Santos; Oswaldo Francisco de Almeida Júnior

A competência em informação e sua avaliação sob a ótica da mediação da informação: reflexões e aproximações teóricas

Existem programas que foram estruturados para desenvolver atividades básicas de identificação, acesso, avaliação e apropriação da informação, diferenciando-se com relação às atividades pré e pós-pesquisa. Estes fornecem parâmetros relacionados ao acesso físico e intelectual dos materiais em todos os formatos, orientação para desenvolver habilidades de pensar, ouvir, ver e estimular o interesse pela leitura, como também verificam quais competências e habilidades devem ser desenvolvidas.

No entanto, cada vez mais as organizações devem incorporar programas de competência em informação. Existe, por conseguinte, uma necessidade para desenvolver métodos de avaliação e ferramentas para avaliar o seu impacto positivo. Na Espanha, por exemplo, esta necessidade está se tornando peremptória em bibliotecas escolares, públicas e universidades. Isso também está se tornando bastante claro nas recomendações e documentos emitidos por organismos internacionais como a Federação Internacional de Associações de Bibliotecas e Instituições (IFLA) e a Organização das Nações Unidas para a Educação, a Ciência e a Cultura (UNESCO), bem como em atividades de associações de outros países, como o Institute of Information Literacy (IIL) e o National Forumon Information Literacy (NFIL) nos Estados Unidos, a Society of College, National and University Libraries (SCONUL) na Inglaterra, NordINFOLIT na Escandinávia e Australian and New Zealand Information Literacy (ANZIIL). Muitas dessas organizações têm proposto modelos de avaliação que estão baseados no uso de questionários e pesquisas e que têm sido aplicados aos programas de desenvolvimento da competência em informação em várias áreas e instituições. Esta é uma tendência lógica, uma vez que a avaliação é um constituinte, parte essencial da competência no acesso e uso da informação. No entanto, estas iniciativas transitam entre as propostas com base em modelos e métodos e sua aplicação imediata na forma de questionários e pesquisas. O debate sobre o melhor sistema de avaliação da competência em informação já existe e foi evidenciado pela IFLA em sua seção especial denominada InfoLit. (MARZÁL, 2010, tradução nossa).

Assim, para a implantação e avaliação de programas de competência em informação, foram criadas diretrizes e normas para auxiliar e nortear profissionais na estruturação e planejamento das atividades. Dentre vários, destacamos as 
Regina Célia Baptista Belluzzo; Camila Araújo dos Santos; Oswaldo Francisco de Almeida Júnior

A competência em informação e sua avaliação sob a ótica da mediação da informação: reflexões e aproximações teóricas

"Características de los programas de alfabetización en información que sirven como ejemplo de las mejores prácticas" de autoria da Association of College and Research Libraries (ACRL, 2003), que oferece embasamento teórico sobre como determinar os módulos de um programa. E o documento Guidelines on information literacy for life long learning, da instituição International Federation of Library Associations and Institutions (IFLA, 2006), cuja finalidade é servir como subsídio para pedagogos e bibliotecários desenvolverem e implantarem um programa de atividades de competência em informação nas instituições, especialmente nos países onde a prática é incipiente, uma vez que podem ser revisadas, alteradas ou adaptadas de acordo com a realidade institucional.

Cabe ressaltar que avaliar a competência em informação não significa medir o conhecimento adquirido pelas pessoas, pois julgamos o conhecimento imensurável, mas sim se estas adquiriram competências e habilidades necessárias para a execução de uma tarefa informacional. A avaliação tem por objetivo verificar se as competências e habilidades foram apropriadas pelas pessoas, e se de fato, desenvolveram o senso crítico em relação ao universo informacional.

A avaliação é um dos aspectos mais importantes da competência em informação, pois possibilita determinar os efeitos e transformações que os programas proporcionam para a instituição, para os membros da instituição e principalmente para os estudantes, por isso considera-se que "[...] a avaliação é uma parte de um processo contínuo de melhoria" (RADCLIFF et. al, 2007, p. 4). A avaliação é um elemento de aprendizagem e um modo de motivar e incentivar os sujeitos no processo de busca, recuperação e apropriação da informação.

A avaliação pode ocorrer em diferentes estágios dos programas de competência em informação e tem a função de apontar, acompanhar e possibilitar a apropriação de aspectos que devem ser trabalhados nos programas de competência e no aproveitamento do discente, indicando a necessidade de adaptação e aperfeiçoamentos. Assim, especificam-se os três tipos de avaliação da aprendizagem dos estudantes, segundo a International Federation of Library Associations and Institutions (IFLA, 2006): 
Regina Célia Baptista Belluzzo; Camila Araújo dos Santos; Oswaldo Francisco de Almeida Júnior

A competência em informação e sua avaliação sob a ótica da mediação da informação: reflexões e aproximações teóricas

\begin{tabular}{|c|c|c|}
\hline $\begin{array}{l}\text { Prescritiva ou } \\
\text { diagnóstica }\end{array}$ & Formativa & Somativa \\
\hline $\begin{array}{c}\text { Avalia as habilidades } \\
\text { informacionais antes do } \\
\text { programa de } \\
\text { desenvolvimento da } \\
\text { competência em } \\
\text { informação, guiando o } \\
\text { conteúdo e a pedagogia } \\
\text { do curso }\end{array}$ & $\begin{array}{c}\text { Realizada durante o } \\
\text { programa de } \\
\text { desenvolvimento da } \\
\text { competência em } \\
\text { informação, permitindo } \\
\text { ajustar os métodos } \\
\text { empregados pelos } \\
\text { docentes e acompanhar a } \\
\text { aprendizagem }\end{array}$ & $\begin{array}{c}\text { Realizada ao final do } \\
\text { programa de } \\
\text { desenvolvimento de } \\
\text { habilidades informacionais }\end{array}$ \\
\hline
\end{tabular}

Fonte: Adaptado de IFLA (2006, p. 45).

A avaliação se faz necessária, pois,

[...] é ela quem direciona qualquer mudança, transformação, realinhamento, manutenção e, até mesmo, o fim de uma ação. Ela não só indica a necessidade dessa reorganização, como também determina os rumos, os caminhos, as trilhas a serem seguidas. Todo o planejamento, incluindo os seus vários componentes, pode ser completamente alterado. (ALMEIDA JUNIOR, 2003, p. 107).

Relacionando o exposto com a mediação da informação, entendemos que ao avaliar as competências e habilidades em informação, podemos verificar parcelas conscientes da apropriação da informação, uma vez que as transformações do conhecimento do mediado nem sempre são percebidas ou entendidas de imediato por ele próprio. A apropriação dá-se tanto no âmbito consciente como no inconsciente, sendo, neste último caso, difícil de ser identificada até mesmo pelo sujeito receptor.

A avaliação da competência em informação, entendida como um processo, não é neutra sendo então uma interferência, elemento partícipe da mediação da informação.

Avaliar as competências e habilidades em informação é uma forma de verificar se a apropriação da informação foi internalizada, já que anterior à apropriação da informação, todo sujeito avalia se o seu conhecimento adquirido pelas ações de interferência (mediação e competência) será suficiente para que tenha um posicionamento pró-ativo, analítico, reflexivo, crítico e independente na busca, recuperação e uso de informações. 
Regina Célia Baptista Belluzzo; Camila Araújo dos Santos; Oswaldo Francisco de Almeida Júnior

A competência em informação e sua avaliação sob a ótica da mediação da informação: reflexões e aproximações teóricas

\section{CONSIDERAÇÕES FINAIS}

Buscou-se explanar neste trabalho, a relação entre três temáticas de forma a contribuir para o enriquecimento das discussões na área. Tais discussões não são conclusivas, pois podem suscitar novos debates e reflexões, não se esgotando em si mesmas.

Ao se realizar a analogia entre as temáticas, ficou evidente a importância da mediação da informação no fazer do profissional da informação, pois esta deixa claro uma interferência necessária, para que o profissional possa lidar com ela de maneira a amenizar / minimizar possíveis problemas que dela decorram.

Por meio da presente discussão, denotamos a importância da mediação da informação na competência em informação e sua avaliação, visto que esta evidencia e destaca a preocupação com a apropriação da informação pelo usuário.

A competência em informação também pode ser considerada como uma ação de interferência, assim como a mediação da informação, pois ambas preocupam-se com a formação de um cidadão crítico e reflexivo frente ao mundo informacional e tecnológico.

Ficou evidente que, em sendo anterior ao processo de apropriação da informação, determinadas competências e habilidades devem ser desenvolvidas e incorporadas para que as informações mediadas sejam assimiladas, apropriadas e transformadas em conhecimento significativo para o mediado.

A avaliação tornou-se um tópico extremamente importante no campo da competência em informação, e também é recomendável que se torne uma linha de prioridade em pesquisa na área de Ciência da Informação. A incorporação de avaliação em programas de competência em informação não deve ser reduzida tão somente a um sistema de qualificação. Pelo contrário, deve delinear um modelo específico para desenvolvimento dessa competência. Modelos de avaliação, métodos e instrumentos devem ser submetidos a um processo articulado de convergência e confluência, e tornar-se uma segunda linha de investigação prioritária em Ciência da Informação.

A competência em informação e sua avaliação sob a ótica da mediação da informação são ações de interferência que propiciam o acesso e uso da informação 
Regina Célia Baptista Belluzzo; Camila Araújo dos Santos; Oswaldo Francisco de Almeida Júnior

A competência em informação e sua avaliação sob a ótica da mediação da informação: reflexões e aproximações teóricas

de forma crítica e reflexiva para a internalização de atitudes pró-ativas em direção à sociedade do conhecimento, que pretende ser socialmente coesa e inclusiva, sendo elementos fundamentais para a definição de estratégias e ações que precisam ser tomadas como garantia do exercício pleno da cidadania.

\section{REFERÊNCIAS}

ALMEIDA JUNIOR, Oswaldo Francisco de. Leitura, mediação e apropriação da informação. In: SANTOS, J.P. (Org.). A leitura como prática pedagógica na formação do profissional da informação. Rio de Janeiro: Fundação Biblioteca Nacional, 2007. p. 33-45.

ALMEIDA JUNIOR, Oswaldo Francisco de. Mediação da informação: ampliando o conceito de disseminação. In: VALENTIM, Marta Lígia Pomim. (Org.). Gestão da informação e do conhecimento no âmbito da Ciência da Informação. São Paulo: Polis: Cultura Acadêmica, 2008. p. 41-54.

ALMEIDA JUNIOR, Oswaldo Francisco de. Mediação da informação e múltiplas linguagens. Pesquisa Brasileira em Ciência da Informação, Brasília, v. 2, n. 1, p. 89-103, 2009.

AMERICAN ASSOCIATION OF SCHOOL LIBRARIANS. Information power: building partnerships for learning. Chicago: ALA, 1998.

ARENAS, Judith Licea de. La Evaluación de laAlfabetización Informacional: principios, metodologías y retos. Anales de Documentacion, n. 10, 2007, p. 215232. Disponível em: <http://dialnet.unirioja.es/servlet/articulo?codigo=2340436.>. Acesso em: 02 nov. 2008.

ASSOCIATION OF COLLEGE AND RESEARCH LIBRARIES.Características de los programas de alfabetización en información que sirven como ejemplo de las mejores prácticas.Estados Unidos, 2003. Disponível em:

<http://eprints.rclis.org/5931/>. Acesso em: 20 abr. 2014.

BELLUZZO, Regina Célia Baptista. Educação de usuários de bibliotecas universitárias: da conceituação e sistematização ao estabelecimento de diretrizes. 1989. 107f. Dissertação (Mestrado em Ciências da Comunicação) - Escola de Comunicação e Artes da Universidade de São Paulo, São Paulo, 1989. 
Regina Célia Baptista Belluzzo; Camila Araújo dos Santos; Oswaldo Francisco de Almeida Júnior

A competência em informação e sua avaliação sob a ótica da mediação da informação: reflexões e aproximações teóricas

BELLUZZO, Regina Célia Baptista. A information literacy como competência necessária à fluência científica e tecnológica na sociedade da informação: uma questão de educação. In: SIMPÓSIO DE ENGENHARIA DA PRODUÇÃO DA UNESP, 7., 2001. Anais... Bauru: UNESP, 2001. Disponível em:

<http://www.simpep.feb.unesp.br/ana8.html>. Acesso em: 12 fev. 2013.

BELLUZZO, Regina Célia Baptista Belluzzo. Como desenvolver a competência em informação $(\mathrm{Cl})$ : uma mediação integrada entre a biblioteca e a escola. CRB-8

Digital, São Paulo, v. 1, n. 2, p. 11-14, 2008. Disponível em:

<http://revista.crb8.org.br/index.php/crb8digital/article/viewFile/25/25>.

Acesso em: 20 abr. 2014.

DUDZIAK, Elisabeth Adriana. A InformationLiteracy e o papel educacional das bibliotecas. 2001. 187f. Dissertação (Mestrado em Ciência da Informação e Documentação) - Escola de Comunicação e Artes da Universidade de São Paulo, São Paulo, 2001.

DUDZIAK, Elisabeth Adriana. Informationliteracy e o papel educacional das bibliotecas e do bibliotecário na construção da competência em informação. In: CONGRESSO BRASILEIRO DE CIÊNCIAS DA COMUNICAÇÃO, 25., 2002, Salvador. Anais... São Paulo: Intercom, 2002. Disponível em: <http://reposcom.portcom.intercom.org.br/handle/1904/19262>.Acesso em: 13 mar. 2007.

DUDZIAK, Elisabeth Adriana. Informationliteracy: princípios, filosofia e prática.

Ciência da Informação, Brasília, v. 32, n. 1, p. 23-35, 2003.

GIL, Antonio Carlos. Métodos e técnicas de pesquisa social. 6. ed. São Paulo: Atlas, 2012.

GONSALVES, Elisa Pereira. Conversas sobre iniciação à pesquisa científica. Campinas: Alínea, 2001.

INTERNATIONAL FEDERATION OF LIBRARY ASSOCIATIONS AND INSTITUTIONS. Guidelines on information literacy for lifelong learning.

Estados Unidos, 2006. Disponível em: <http://www.ifla.org/files/assets/informationliteracy/publications/ifla-guidelines-es.pdf>.

Acesso em: 17 abr. 2014.

MARZÁL, Miguel Ángel. Evaluation of information literacy programmes in higher education: strategies and tools. Revista de Universidad y Sociedad Del Conocimiento (RUSC), Barcelona, v. 7, n. 2, p. 26-36, 2010. Disponível em: <http://rusc.uoc.edu/ojs/index.php/rusc/article/view/v7n2-marzal/v7n2-marzal-eng>. Acesso em: 20 fev. 2014. 
Regina Célia Baptista Belluzzo; Camila Araújo dos Santos; Oswaldo Francisco de Almeida Júnior

A competência em informação e sua avaliação sob a ótica da mediação da informação: reflexões e aproximações teóricas

RADCLIFF, Carolyn J. et al. A practical guide to information literacy assessment for academic librarians. Londres: Libraries, 2007. 177 p.

VARELA, Aida Varela. A explosão informacional e a mediação na construção do conhecimento. In: MIRANDA, A.; SIMEÃO, E. (Org.). Alfabetização digital e acesso ao conhecimento. Brasília: Universidade de Brasília, Departamento de Ciência da Informação e Documentação, 2006. p.15-32.

\section{Title}

The information literacy and its assessment under the perspective of information mediation: reflections and theoretical approaches

\section{Abstract}

Introduction: The study debates the existing theoretical approach between the themes information literacy and its assessment with the information mediation.

Objective: To expose, by means of the analogy among the themes (information literacy and its assessment and the information mediation), the similarities of these processes in order to provide a better understanding to their applicability.

Methodology: The research is bibliographic and qualitative in nature.

Results: As a result, it was found that information literacy is an act of interference, as well as the information mediation, since both are concerned with the formation of critical and reflective citizens across the informational world. The information literacy assessment is a way to check if the ownership information was internalized by people.

Conclusions: The development of information literacy and its assessment from the perspective of information mediation are actions of interference that provide the construction of critical and reflective knowledge in people to the internalisation of pro-active steps to wisely access and use information in contemporary society.

Key words: Information literacy. Information literacy assessment. Information mediation.

\section{Título}

La alfabetización y sua evaluación desde la perspectiva de la mediación de la información: reflexiones y aproximaciones teóricas

\section{Resumen}

Introducción: En este estudio se analiza desde un enfoque teórico la relación existente entre los temas alfabetización informacional y su evaluación con la mediación de la información. 
Regina Célia Baptista Belluzzo; Camila Araújo dos Santos; Oswaldo Francisco de Almeida Júnior

A competência em informação e sua avaliação sob a ótica da mediação da informação: reflexões e aproximações teóricas

Objetivo: Exponer, a través de analogías entre temáticas (alfabetización informacional y su evaluación y la mediación de la información), las similitudes entre estos procesos, con la finalidad de proporcionar una compresión mejor para la aplicación de los mismos.

Metodología: La investigación que se presenta es de naturaleza cualitativa y con carácter bibliográfico.

Resultados: Como resultado, se comprueba que la alfabetización informacional es un evento de interferencia al igual que la mediación de información, ambos conceptos están relacionados con la formación de un ciudadano crítico y reflexivo que enfrenta a una sociedad caracterizada por el uso de la información. La evaluación de la alfabetización informacional es una forma de demostrar si la información fue interiorizada y comprendida por las personas.

Conclusiones: El desarrollo de la alfabetización informacional y su evaluación desde la perspectiva de la mediación de la información constituyen acciones que proporcionan la construcción de un conocimiento crítico y reflexivo en las personas, para que de esta forma puedan conocer medidas pro-activas para acceder y utilizar la información de forma inteligente en la sociedad contemporánea.

Palabras clave: Alfabetización informacional. Evaluación de la alfabetización informacional. Mediación de la información.

Recebido em: 15.07.2014

Aceito em: 05.10.2014 